\title{
Antimicrobial susceptibility of Neisseria gonorrhoeae isolates from patients attending a public referral center for sexually transmitted diseases in Belo Horizonte, State of Minas Gerais, Brazil
}

\author{
Lígia Maria Bedeschi Costa ${ }^{[1],[2],[3], ~ E ̂ n i o ~ R o b e r t o ~ P i e t r a ~ P e d r o s o ~}{ }^{[4]}$, Virgílio Vieira Neto ${ }^{[2],[4],}$ \\ Viviane Cata Preta Souza ${ }^{[3]}$ and Maria Juliana Bastos Teixeira ${ }^{[2],[3]}$
}

[1]. Programa de Pós-Graduação em Ciências da Saúde: Infectologia e Medicina Tropical, Faculdade de Medicina, Universidade Federal de Minas Gerais, Belo Horizonte, MG. [2]. Serviço de DST/SCS, Unidade de Referência Secundária-Centro-Sul, Secretaria Municipal da Saúde, Belo Horizonte, MG. [3]. Laboratório de Microbiologia, Hospital João XXIII, Fundação Hospitalar do Estado de Minas Gerais, Belo Horizonte, MG. [4]. Faculdade de Medicina, Universidade Federal de Minas Gerais, Belo Horizonte, MG.

\begin{abstract}
Introduction: The aim of this study was to determine the antimicrobial susceptibility of Neisseria gonorrhoeae isolates obtained from patients attending a public referral center for sexually transmitted diseases and specialized care services (STD/SCS) in Belo Horizonte, Brazil. Methods: Between March 2011 and February 2012, 201 specimens of Neisseria gonorrhoeae were consecutively obtained from men with symptoms of urethritis and women with symptons of cervicitis or were obtained during their initial consultation. The strains were tested using the disk diffusion method, and the minimum inhibitory concentrations of azithromycin, cefixime, ceftriaxone, ciprofloxacin, chloramphenicol, penicillin, tetracycline and spectinomycin were determined using the E-test. Results: The specimens were 100\% sensitive to cefixime, ceftriaxone and spectinomycin and exhibited resistances of 4.5\% (9/201), $21.4 \%$ (43/201), $11.9 \%$ (24/201), 22.4\% (45/201) and 32.3\% (65/201) to azithromycin, ciprofloxacin, chloramphenicol, penicillin and tetracycline, respectively. Intermediate sensitivities of $17.9 \%$ (36/201), 4\% (8/201), $16.9 \%(34 / 201), 71.1 \%(143 / 201)$ and $22.9 \%$ (46/201) were observed for azithromycin, ciprofloxacin, chloramphenicol, penicillin and tetracycline, respectively. The specimens had plasmid-mediated resistance to penicillin PPNG 14.5\% (29/201) and tetracycline TRNG 11.5\% (23/201). Conclusions: The high percentage of detected resistance to penicillin, tetracycline, chloramphenicol and ciprofloxacin indicates that these antibiotics are not appropriate for gonorrhea treatment at the Health Clinic and possibly in Belo Horizonte. The resistance and intermediate sensitivity of these isolates indicates that caution is recommended in the use of azithromycin and emphasizes the need to establish mechanisms for the surveillance of antimicrobial resistance for the effective control of gonorrhea.
\end{abstract}

Keywords: Neisseria gonorrhoeae. Gonorrhea. Antimicrobial susceptibility. E-test. Disk diffusion.

\section{INTRODUCTION}

Gonorrhea remains a serious public health problem and is the second most prevalent bacterial infection and sexually transmitted disease worldwide, with 106 million new cases annually ${ }^{1,2}$. Its incidence is higher in underdeveloped countries and developing countries but remains unacceptably high in developed countries, particularly among those associated with vulnerable populations, marginalized ethnicities or sexual

Address to: Dra. Lígia Maria Bedeschi Costa. Rua Xavier da Veiga 178/202, Bairro Minas Brasil, 30730-220 Belo Horizonte, MG, Brasil.

Phone: 5531 3462-0776; 5531 9223-0800; Fax: 5531 3476-4355

e-mail: ligiabedeschi@yahoo.com.br

Received 21 January 2013

Accepted 22 May 2013 orientations $^{3,4}$. Gonorrhea can cause serious complications such as epididymitis, pelvic inflammatory disease, ectopic pregnancy and infertility and can also enhance the acquisition and transmission of human immunodeficiency virus (HIV) ${ }^{2,5}$.

Neisseria gonorrhoeae has a high ability to develop resistance to antimicrobials, resulting in the progressive loss of cheap and effective treatments and the need to use more expensive drugs that are inaccessible in many countries ${ }^{4}$. An issue of current significance is the appearance of strains of $N$. gonorrhoeae that are resistant to multiple antimicrobials, including penicillin, tetracycline, macrolides, fluoroquinolone and spectinomycin. The emergence of resistance occurs, in general, by rapid diffusion and is highly prevalent ${ }^{6,7}$. Over the past three years, gonococcal resistance to third-generation cephalosporins, which are recommended as the first choice for treatment, has emerged rapidly in Japan and other countries. This resistance constitutes an epidemiological situation that prevents healing and increases the likelihood of the occurrence of serious consequences associated with gonorrhea ${ }^{8}$. 
The control of gonorrhea is a vital issue to public health and requires an integrated approach to provide effective treatment that breaks the chain of transmission and reduces complications. Knowledge of local susceptibility patterns of $N$. gonorrhoeae is essential to establish the best treatment ${ }^{9,10}$. Control of gonococcal infection requires the continuous and high-quality surveillance of resistance ${ }^{2,6}$; however, few studies on this subject have been conducted in Brazil. The current study provides insight into the resistance of Neisseria gonorrhoeae in Belo Horizonte, Minas Gerais. This study also contributes to the collection of epidemiological data to support the formulation of health policies for disease prevention and control and will facilitate the standardization of the most appropriate and effective treatment.

\section{METHODS}

This study is a descriptive and cross-sectional observational study that was conducted at the Department of STD/SCS, Secondary Reference Unit Centre-South (SRU-CS), the Secretaria Municipal de Saúde of Belo Horizonte and the Microbiology Laboratory of Hospital João XXIII, Fundação Hospitalar do Estado de Minas Gerais.

The isolates of Neisseria gonorrhoeae were consecutively obtained from men with symptoms of urethritis and women with symptoms of cervicitis or were obtained during their initial consultation at the STD/SCS Department during the period March 2011 to February 2012. A total of 232 isolates of Neisseria gonorrhoeae were obtained, of which 201 were viable for use in the proposed analysis.

Eligible patients underwent the collection of endocervical or urethral material according to the appropriate technique ${ }^{11}$. Strains were cultivated and identified according to standard procedures $^{12,13}$. The collected material was inoculated directly onto modified Thayer Martin (Polyvitex/VCAT3-Biomérieux ${ }^{\circledR}$ ) and incubated immediately at $35.5^{\circ} \mathrm{C}$ to $36.5^{\circ} \mathrm{C}$ in an atmosphere of $5 \% \mathrm{CO}_{2}$ for $72 \mathrm{~h}$. Morphologically suggestive colonies were screened by Gram staining and by their positive responses to the oxidase and catalase tests. Positive colonies were subcultivated on chocolate supplement agar (Chocolate Polyvitex/Biomérieux $\left.{ }^{\circledR}\right)$, and their identification was confirmed using the automatic system VITEK II ${ }^{\circledR}$ (NH - Biomérieux). The production of $\beta$-lactamase was tested by the chromogenic cephalosporin method (Cefinase Paper Disc- BBL ${ }^{\circledR}$ ).

The susceptibility of the Neisseria gonorrhoeae isolates to azithromycin, cefixime, ceftriaxone, ciprofloxacin, chloramphenicol, penicillin, tetracycline and spectinomycin was tested by the disk diffusion ${ }^{14,15}$ and E-test ${ }^{16}$ (Biomérieux ${ }^{\circledR}$ ) methods, and minimum inhibitory concentrations (MICs) were determined. The tests were performed on GC agar supplemented with $1 \%$ growth factors (GC Agar with 1\% Vitox/PlastLabor ${ }^{\circledR}$ ) according to the methodology of the Clinical Laboratory Standards Institute (CLSI) and the Centers for Disease Control $(\mathrm{CDC})^{14,15,17}$. Inocula were prepared using colonies that had been grown for $24 \mathrm{~h}$ by direct suspension in sterile saline to a turbidity equivalent to the $0.5 \mathrm{McF}$ arland standard; inocula were adjusted using a turbidimeter. Within $15 \mathrm{~min}$, the suspension was inoculated on the surface of a 150-mm diameter GC agar plate. After the absorption of the inoculum, antimicrobial discs $\left(\mathrm{OXOID}{ }^{\circledR}\right)$ and E-test strips (Biomerieux $\left.{ }^{\circledR}\right)$ were applied. The plates were incubated at $35.5^{\circ} \mathrm{C}$ to $36.5^{\circ} \mathrm{C}$ in an atmosphere of $5 \% \mathrm{CO}_{2}$ for 20 to $24 \mathrm{~h}$.

The susceptibility was interpreted according to the criteria defined by CLSI ${ }^{15}$. The CDC criteria were used for azithromycin, whereas the method of Dick Van and collaborators was used for chloramphenicol ${ }^{12,17}$. The isolates were classified as having a presumed plasmid-mediated resistance to penicillin (PPNG) when they were $\beta$-lactamase positive and a presumed resistance to tetracycline (TRNG) when the MIC was $\geq 16 \mu \mathrm{g} / \mathrm{mL}^{15}$. Chromosomal resistance to penicillin was defined as an $\mathrm{MIC} \geq 2 \mu \mathrm{g} / \mathrm{mL}$ in ß-lactamase-negative specimens, and tetracycline resistance was defined for specimens with MICs between 2 and $<16 \mu \mathrm{g} / \mathrm{mL}$.

Quality control was performed using reference strains of Neisseria gonorrhoeae ATCC 49226 (American Type Culture Collection), which were kindly provided by Professor Sergio Eduardo Longo Fracalanzza, Universidade Federal of Rio de Janeiro.

Information was obtained on the socio-demographic and behavioral characteristics of patients using a questionnaire and medical records.

Statistical analysis was performed using SPSS software version 17.0. For the age variable, an estimated median was performed, as with the measures of variability. For the qualitative variables, proportions were performed.

\section{Ethical considerations}

This study was authorized by the Research Ethics Committee of the the Secretaria Municipal de Saúde of Belo Horizonte and Universidade Federal de Minas Gerais, and specimens were collected after the subjects agreed with and completed the Free and Informed Consent Terms.

\section{RESULTS}

\section{Evaluation of the susceptibility profile}

The susceptibility of 201 isolates of Neisseria gonorrhoeae to azithromycin, cefixime, ceftriaxone, ciprofloxacin, chloramphenicol, penicillin, tetracycline and spectinomycin was assessed as shown in Table $\mathbf{1 .}$

All strains were susceptible to ceftriaxone, cefixime $(\mathrm{MIC} \leq 0.25 \mu \mathrm{g} / \mathrm{mL})$ and spectinomycin $(\mathrm{MIC} \leq 32 \mu \mathrm{g} / \mathrm{mL})$. Resistance to ciprofloxacin was observed in $21.4 \%$ (43/201) of specimens (MIC $\geq 1 \mu \mathrm{g} / \mathrm{mL}$ ); chloramphenicol in $11.9 \%(24 / 201)$ (MIC $\geq 2 \mu \mathrm{g} / \mathrm{mL}$ ); azithromycin in 4.5\% (9/201) (MIC $\geq 1 \mu \mathrm{g} / \mathrm{mL}$ ); penicillin in $22.4 \%(45 / 201)$; and tetracycline in $32.3 \%(65 / 201)$ (MIC $\geq 2 \mu \mathrm{g} / \mathrm{mL}$ ).

High levels of resistance to azithromycin $(12 \mu \mathrm{g} / \mathrm{mL})$, ciprofloxacin $(>32 \mu \mathrm{g} / \mathrm{mL})$, chloramphenicol $(12 \mu \mathrm{g} / \mathrm{mL})$, penicillin $(256 \mu \mathrm{g} / \mathrm{mL})$ and tetracycline $(32 \mu \mathrm{g} / \mathrm{mL})$ were observed. Concomitant resistance to various antimicrobial agents was detected, such as azithromycin and chloramphenicol 
TABLE 1 - Susceptibility and MIC, as determined by E-test, of 201 strains of Neisseria gonorrhoeae sampled in the Department of Sexually Transmitted Diseases/Specialized Care Services of the SRU-CS/SMSA in Belo Horizonte, State of Minas Gerais, Brazil.

\begin{tabular}{|c|c|c|c|c|c|c|c|c|c|}
\hline \multirow[b]{3}{*}{ Antimicrobialagent } & \multicolumn{6}{|c|}{ Number of isolates $(\%)$} & & & \\
\hline & \multicolumn{2}{|c|}{ susceptible } & \multicolumn{2}{|c|}{ intermediate } & \multicolumn{2}{|c|}{ resistant } & \multicolumn{3}{|c|}{ MIC $(\mu \mathrm{g} / \mathrm{mL})$} \\
\hline & $\mathrm{n}$ & $\%$ & $\mathrm{n}$ & $\%$ & $\mathrm{n}$ & $\%$ & MIC $50 \%$ & MIC90\% & Range \\
\hline Azithromycin & 156 & 77.6 & 36 & 17.9 & 9 & 4.5 & 0.125 & 0.38 & $0.016-12$ \\
\hline Cefixime & 201 & 100.0 & - & - & 0.016 & 0.016 & $0.016-0.125$ & & \\
\hline Ceftriaxone & 201 & 100.0 & - & - & 0.016 & 0.016 & $0.002-0.032$ & & \\
\hline Chloramphenicol & 143 & 71.1 & 34 & 16.9 & 24 & 11.9 & 0.38 & 2 & $0.125-12$ \\
\hline Penicillin & 13 & 6.5 & 143 & 71.1 & 45 & 22.4 & 0.25 & 6 & $0.008-256$ \\
\hline Tetracycline & 90 & 44.8 & 46 & 22.9 & 65 & 32.3 & 0.5 & 16 & $0.032-32$ \\
\hline Spectinomycin & 201 & 100.0 & - & - & 12 & 16.0 & $4.000-24$ & & \\
\hline
\end{tabular}

MIC: minimum inhibitory concentration; SRU-CS/SMSA: Secondary Reference Unit-Centre South/Secretaria Municipal de Saúde.

(1 isolate); ciprofloxacin and chloramphenicol (5 isolates); azithromycin, ciprofloxacin and chloramphenicol (2 isolates); azithromycin, ciprofloxacin, penicillin and chloramphenicol ( 2 isolates); azithromycin, ciprofloxacin, chloramphenicol, tetracycline and penicillin ( 2 isolates); and ciprofloxacin, chloramphenicol, penicillin and tetracycline ( 3 isolates), with two of them presenting a high level of resistance to ciprofloxacin (MIC $>32 \mu \mathrm{g} / \mathrm{mL}$ ).

Several categories of resistance to penicillin and tetracycline were identified $^{13,15}$ (Table 2). PPNG was detected in $14.5 \%$ $(29 / 201)$ of the isolates and TRNG in $11.5 \%(23 / 201)$, whereas $5 \%$ (10/201) presented both phenotypes (PPNG/TRNG).

\section{Frequency of gonorrhea in the Department of STD/SCS of the SRU-CS/SMSA in Belo Horizonte}

During the period March 2011 to February 2012, 7,646 patients were cared for in the Department of STD/SCS of the SRU-CS/SMSA in Belo Horizonte, including 5,851 (76.5\%) males and 1,795 (23.5\%) females. Of these, 676 men and 583 women underwent endocervical or urethral sample collection. There were 287 cases of gonorrhea, with a relative frequency of $40.5 \%$ (274/676) for men and 2.2\% (13/583) for women.

\section{Studied population at the Department of STD/SCS of the SRU-CS}

The 201 analyzed specimens of Neisseria gonorrhoeae were obtained from 200 patients of both sexes, including two specimens from one patient who returned to the clinic with a new infection. Of the patients studied, 95\% (190/200) were male, and 5\% (10/200) were female, with ages ranging from 14 to 61 years (median 26 years) and 17 to 40 years (median 22 years), respectively. Among the men, 21\% (40/200) declared that they were men who have sex with men (MSM).

The degree of formal schooling at the elementary, secondary and university level was 64\% (128/200), 32.5\% (65/200) and $3.5 \%(7 / 200)$, respectively. A total of $46.6 \%(83 / 178)$ of the patients reported a monthly income of up to 1 minimum salary. Of those patients, 38.5\% (32/83) had no income, 40.4\% (72/178) had between 1 and 2 salaries, and 12.9\% (23/178) had over 2 salaries. A total of $85.5 \%(171 / 200)$ of the patients resided in Belo Horizonte city, and 14.5\% (29/200) resided in other municipalities of the metropolitan area: $5.5 \%(11 / 200)$ resided in Ribeirão das Neves, $3.5 \%$ (7/200) in Contagem, $2.5 \%(5 / 200)$ in Santa Luzia, $1.5 \%(3 / 200)$ in Sabará and $0.5 \%(1 / 200)$ in

TABLE 2 - Plasmid-mediated and chromosomal-mediated resistance of 201 Neisseria gonorrhoeae isolates to penicillin and tetracycline.

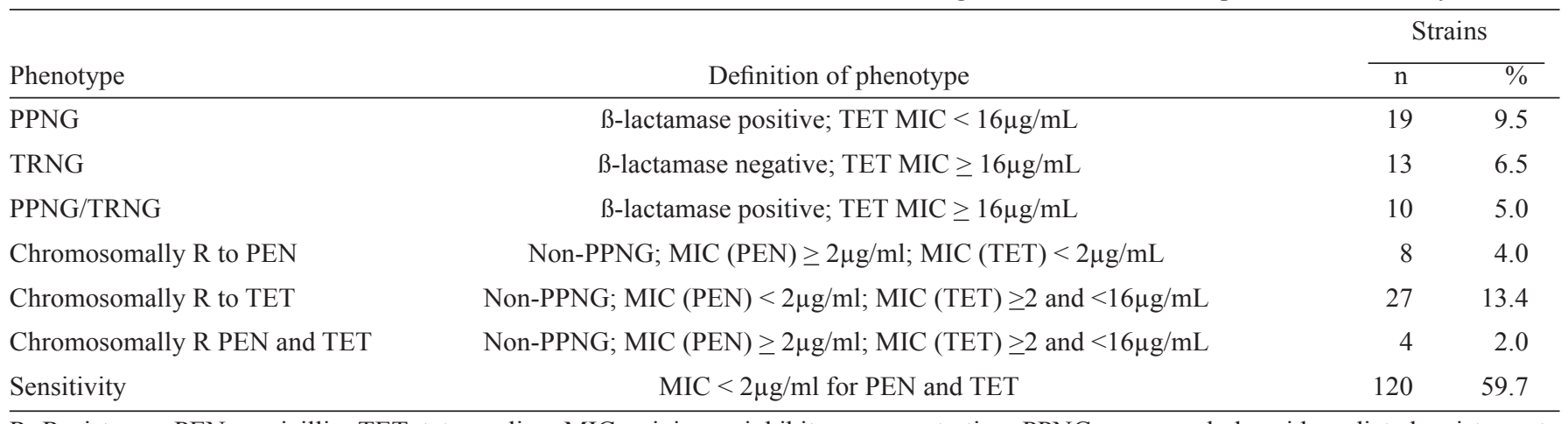

R: Resistance; PEN: penicillin; TET: tetracycline; MIC: minimum inhibitory concentration; PPNG: presumed plasmid-mediated resistance to penicillin; TRNG: presumed resistance to tetracycline. 
Nova Lima, Betim and Ibirité. Four (2\%) patients reported that they did not have a fixed place of residence because they are homeless.

The use of condoms was reported as follows: never used, $31.2 \%$ (62/199); used sporadically, 45.2\% (90/199); and not used with a regular partner, $11.6 \%$ (23/199). Regular use was reported by $12 \%(24 / 199)$ of the patients, of which $25 \%(6 / 24)$ did not use them during oral sex. With respect to the patients' sexual partners in the last year, $16.1 \%(31 / 193)$ reported a steady partner for more than 6 months, $14.5 \%(28 / 193)$ had a new partner in the last 3 months, and $69.4 \%(134 / 193)$ had more than one partner in the last 3 months. A total of $13.9 \%$ (27/193) reported having a single partner, $47.8 \%(92 / 193)$ had 2-5 partners, 36.8\% (71/193) had 6-20 partners, and 1.6\% (3/193) had more than 20 partners in the last year. There was a history of STDs in $44 \%$ (88/200) of the patients; of these, $43 \%(38 / 88)$ reported previous infection with gonorrhea. A total of $13.5 \%$ (27/200) of the patients reported the use of drugs such as marijuana, cocaine and crack.

A history of other concomitant STDs was also reported in the patients, including syphilis, 9.5\% (19/200); hepatitis B, 9.5\% (19/200); 5.5\%, HIV (11/199); hepatitis C, $1 \%(2 / 200)$; condyloma, $0.5 \%(1 / 200)$; genital herpes, $3 \%(6 / 200)$; and chancroid, 2\% (4/200). Among women, 80\% (8/10) reported bacterial vaginosis, $20 \%(2 / 10)$ had trichomoniasis, and $10 \%$ $(1 / 10)$ had candidiasis.

Regarding the treatment used, $42.1 \%(83 / 197)$ of patients received $2.5 \mathrm{~g}$ of thiamphenicol in a single dose, $51.8 \%(102 / 197)$ received thiamphenicol combined with $1 \mathrm{~g}$ of azithromycin, $4 \%(8 / 197)$ received only azithromycin, $1 \%(2 / 197)$ received thiamphenicol and $100 \mathrm{mg}$ of doxycycline, $1 \%(2 / 197)$ received thiamphenicol and 500mg of ciprofloxacin, and 1.5\% (3/200) did not return for treatment. Of the patients, $32 \%(64 / 200)$ returned for evaluation; of those, $7.8 \%$ (5/64) remained symptomatic. Of the patients who returned with symptoms, 1 patient had non-gonococcal urethritis, and 4 had gonococcal urethritis, as confirmed by laboratory testing. Among those with gonorrhea, two returned within 7 days with no improvement and were infected with strains of $N$. gonorrhoeae that were resistant to the treatment used (thiamphenicol), but there was no confirmation of treatment failure.

\section{DISCUSSION}

The latest data on the antimicrobial susceptibility of $N$. gonorrhoeae reported in Belo Horizonte were reported in $1984^{18}$; in that study, tetracycline resistance was observed in $5.6 \%$, chloramphenicol in $13.9 \%$ and intermediate sensitivity to penicillin in $15.3 \%$ of the studied patients.

The data reported here reveal a high level of resistance to tetracycline, penicillin, chloramphenicol and ciprofloxacin, as well as intermediate sensitivities to azithromycin, chloramphenicol, penicillin and tetracycline. The occurrence of resistance, except in the case of azithromycin, exceeded the limit of $5 \%$, which does not permit the use of these antimicrobials in the treatment of gonorrhea according to the World Health Organization and the $\mathrm{CDC}^{6,9}$.
The occurrence of resistance to penicillin $(22.4 \%)$ is similar to that reported in Manaus ${ }^{19}(21.8 \%)$ and São Paulo ${ }^{20}(23 \%)$ and higher than that observed in Rio de Janeiro ${ }^{21}(8.7 \%)$. Similar values were observed in Latin America and the Caribbean ${ }^{22}$ (25.3\%), but many studied populations have higher rates of resistance, including Bolivia (62\%), Peru (80\%) and Venezuela ${ }^{23}$ (87\%). The prevalence of PPNG (14.5\%) is similar to that observed in Manaus (14.5\%), higher than that obtained in Rio de Janeiro (8.6\%) and lower than that detected in São Paulo (23\%). The reported rates of resistance are much higher in Africa ${ }^{24}$ (46.4 to $87 \%$ ), Indonesia $(60 \%)^{25}$ and some Latin American countries such as Colombia (56\%) and Bolivia (61\%) ${ }^{23}$.

The tetracycline resistance observed (32.3\%) in this study is similar to that observed in Rio de Janeiro ${ }^{21}$ (33.9\%) and São Paulo ${ }^{20}(30.8 \%)$ and much lower than that in Manaus ${ }^{19}$ $(80 \%)$. These findings are consistent with observations in countries such as Chile (33\%) and Uruguay (32\%) and lower than that obtained in Bolivia (54\%), Peru (90\%) and Venezuela ${ }^{23}$ $(100 \%)$. The frequency of TRNG strains $(11.5 \%)$ is similar to that observed in Manaus (12.7\%) but lower than that detected in Rio de Janeiro (20\%). The frequency reported in this study is also compatible with that observed in Peru (10\%) and higher than that reported in Argentina (5\%) and Uruguay (4\%).

Specimens with resistance to penicillin and tetracycline have been reported in Brazil since 198418,26. Gonorrhea has also become resistant to azithromycin (4.5\%), consistent with observations in Manaus ${ }^{19}$ (6.4\%), but our reported rate is higher than the $20 \%$ intermediate sensitivity observed in Rio de Janeiro $^{21}$. Azithromycin resistance has been reported in several countries such as Uruguay (9\%), Chile (46\%), Peru ${ }^{23}(75 \%)$, the United States of America ${ }^{3}(0.5 \%)$ and Germany ${ }^{27}$ (7.7\%). Although it is not recommended for treatment for gonorrhea in Brazil $^{28}$, azithromycin could be used as a therapeutic option, albeit with caution. In this study, less than $5 \%$ of the specimens were resistant to azithromycin, but we also observed large numbers of specimens with reduced susceptibility.

Ciprofloxacin is recommended as a first-line treatment for gonococcal infections in $\mathrm{Brazil}^{28}$. Ciprofloxacin resistance is greatly increased (21.4\%) compared to other national studies. These studies initially observed decreased susceptibility ${ }^{19,21}$ followed by drug resistance in Manaus ${ }^{23}(2 \%)$, São Paulo ${ }^{29}$ $(3.7 \%)$ and Rio de Janeiro ${ }^{30}(7.7 \%)$. These findings are consistent with a recent study in Rio de Janeiro ${ }^{30}$ that reported $16.5 \%$ resistance in the period 2005 to 2010 and $33.3 \%$ in 2010.

According to the GASPLAC surveillance program ${ }^{31}$, resistance increased in Latin America and the Caribbean from $2 \%$ in 2000 to $30 \%$ in 2009 , reaching $60 \%$ in some countries such as Peru ${ }^{23}$. Many countries, such as the U.S.A $(12.5 \%)^{3}$ and Germany ${ }^{27}(47.7 \%)$, have detected high levels of resistance to ciprofloxacin, and thus its use for the treatment of gonorrhea has been discontinued in these locations $s^{4,32,33}$. In addition, specimens with a high level of resistance to ciprofloxacin (MIC $>32 \mu \mathrm{g} / \mathrm{ml}$ ) that also exhibited resistance to chloramphenicol and tetracycline were identified. These specimens are phenotypically similar to those detected in Manaus $^{34}$, although this similarity has not been confirmed by molecular analysis. 
The $11.9 \%$ resistance to chloramphenicol observed in this study is higher than that obtained in Rio de Janeiro ${ }^{21}(3.5 \%)$ and Manaus $(5 \%)^{23}$ but lower than that observed in Belo Horizonte in $1984^{18}(13.8 \%)$ and in Indonesia $(36.8 \%)^{25}$ and African countries $(57.3 \%)^{24}$.

In the Department of STD/SCS of the SRU-CS, thiamphenicol is commonly used to treat gonorrhea. Ciprofloxacin is also often used in combination with doxycycline or azithromycin for infections concomitant with chlamydia. Azithromycin and ciprofloxacin are also widely used, both for other STDs and for various other community-acquired or nosocomial infections. Although thiamphenicol is no longer recommended by the Ministry of Health ${ }^{28}$, it is still currently used because of its reduced cost, ease of administration and clinical efficacy. The level of resistance to chloramphenicol (an analog of thiamphenicol) is concerning, although it is lower now than in $1984^{18}$, presumably due to reduced use. Nonetheless, the level of resistance still exceeds the percentage of resistance allowed for empirical use. The patients are presumably considered healed, but the return rate is too low (32\%) to ensure the effectiveness of the treatment.

Spectinomycin exhibits excellent sensitivity, but it is only effective for urethral and rectal infections $\mathrm{s}^{33}$. However, Pharyngeal (P) infections are asymptomatic, and although increasing in importance ${ }^{6,7}$, particularly in the MSM population, this site is rarely screened. In addition to the high cost and intramuscular administration of spectinomycin, high-level resistance has emerged quickly when spectinomycin has been used in the past due to a single mutation ${ }^{33}$.

Although no resistance to cephalosporin was observed in this study, all antimicrobials used extensively in the hospital should be monitored. Cefixime, despite its advantage of oral administration, is not available in Brazil.

Factors such as self-medication, possibly due to insufficient control of the sale of antimicrobials, and the lack of medical care for treatment may contribute to the development of resistance.

This study was limited by the impossibility of molecular tests for the detection of resistance mechanisms and the typing of strains. The data originate from an STD health service referral center for healthcare in Belo Horizonte and the metropolitan area, which may have a higher prevalence of resistance than the general population. Further studies are needed to verify the effectiveness of treatment with thiamphenicol.

This study supports the use of third-generation cephalosporins and spectinomycin as a first-choice treatment for gonorrhea in Belo Horizonte. The results of our study confirm the recommendations for the non-use of penicillin and tetracycline and advise against the use of ciprofloxacin. Based on our in vitro results, the rate of resistance to chloramphenicol, which is structurally related to thiamphenicol, discourages its empirical use for the treatment of gonorrhea.

The effective treatment of gonorrhea is important to reduce its transmission and to reduce the transmission of HIV. The continuous monitoring of treatment efficacy and regional systematic surveillance of antimicrobial susceptibility, are critical components of disease control and prevention. Further studies are urgently needed to identify new alternative treatment regimens for gonorrhea.

Patients in the Department of STD/SCS are predominantly young and have multiple partners, a low level of education and income and a history of recurrent STDs. More effective programs to promote health must be developed that include considerations of sexual practices and encourage the practice of safe sex.

The study of the susceptibility of $N$. gonorrhoeae to antimicrobials represents a step toward more efficient therapies. This type of strategy must become a routine part of monitoring reference services of microbial resistance.

\section{ACKNOWLEDGMENTS}

The authors thank the medical staff of SRU/CS, the laboratory teams of STD/SRU-CS and the Microbiology Laboratory Joao XXIII Hospital/Fundação Hospitalar do Estado de Minas Gerais. We also thank Dra. Maria Auxiliadora M.M. Vianna. We gratefully acknowledge PlastLabor for the development of the GC culture medium.

\section{CONFLICT OF INTEREST}

The authors declare that there is no conflict of interest.

\section{FINANCIAL SUPPORT}

The Coordination of Improvement for Higher Education Personnel - (CAPES / Brazil), and The Foundation for Research Support of the State of Minas Gerais (FAPEMIG).

\section{REFERENCES}

1. World Health Organization (WHO). Global action plan to control the spread and impact of antimicrobial resistance in Neisseria gonorrhoeae. Geneva: WHO; 2012. [Cited 2013 January 18] Available from: http:// whqlibdoc.who.int/publications/2012/9789241503501_eng.pdf/.

2. Tapsall JW, Ndowa F, Lewis DA, Unemo M. Meeting the public health challenge of multidrug- and extensively drug-resistant Neisseria gonorrhoeae. Expert Rev Anti Infect Ther 2009; 7:821-834.

3. Centers for disease control and prevention (CDC). Division of STD Prevention. Sexually Transmitted Disease Surveillance 2010. Department of Health and Human Services 2011; (RR-12): 17-31.

4. Tapsall JW. Antibiotic Resistance in Neisseria gonorrhoeae. Clin Infect Dis 2005; 41(suppl IV):263-268.

5. Fleming DT, Wasserheit JN. From epidemiological synergy to public health policy and practice: the contribution of other STD to sexual transmission of HIV infection. Sex Transm Infect 1999; 75:3-17.

6. Workowski KA, Berman SM, Douglas Jr JM. Emerging Antimicrobial Resistance in Neisseria gonorrhoeae: Urgent Need to Strengthen Prevention Strategies. Ann Intern Med 2008; 148:606-613.

7. Gail AB, Sparling PF, Wasserheit JN. The Emerging Threat of Untreatable Gonococcal Infection. N Engl J Med 2012; 366:485-487.

8. Ohnishi M, Golparian D, Shimuta K, Saika T, Hoshina S, Iwasaku K, et al. Is Neisseria gonorrhoeae initiating a future era of untreatable 
gonorrhoea? Detailed Characterization of the First Strain with HighLevel Resistance to Ceftriaxone. Antimicrob Agents Chemother 2011; 55:3538-3545.

9. Organização Mundial da Saúde (OMS). Infecções por gonococos in Orientações para o Tratamento de Infecções Sexualmente Transmissíveis. Genebra, Suíça: OMS; 2005; p.48-49. [Cited 2011 february 15]. Available from: http://whqlibdoc.who.int/publications/portuguese/9248546269 por.pdf Workowski KA, Berman SM. Centers for Disease Control and Prevention. Sexually transmitted diseases treatment guidelines, 2010. MMWR 2010; 59 (RR-12): 49-59.

10. Ministério da Saúde. Secretaria de Vigilância em Saúde. Departamento de DST, Aids e Hepatites Virais. Serie Telelab. Técnicas para Coleta de Secreções. Brasília: MS; 2011. p. 19-28.

11. Van Dyck E, Maheus AZ, Piot P. World Health Organization. Laboratory Diag Sex Trans Dis 1999; 1:1-21.

12. Knap JS. Organización Mundial de la Salud/CDC. Neisseria gonorrhoeae. In: OMS/CDC, editor. Manual de Laboratorio para la Identificación y Prueba de Susceptibilidad a los Antimicrobianos de Patógenos Bacterianos de Importancia para la Salud Pública en el Mundo en Desarrollo Vol. 6. OMS/CDC; 2003. p. 63-102.

13. Clinical and Laboratory Standards Institute (CLSI). Performance Standards for Antimicrobial Disk Susceptibility Tests: Approved Standard- $10^{\text {th }}$ Edition. M02-A1, Vol 23 number 1. CLSI; 2009.

14. Clinical and Laboratory Standards Institute (CLSI). Performance Standards for Antimicrobial Susceptibility Testing; M100-S22. Vol 32, number 3. Twenty-Second Informational Supplement. CLSI; 2012.

15. Van Dyck E, Smet H, Piot P. Comparison of Etest with agar dilution for antimicrobial susceptibility testing of Neisseria gonorrhoeae. J Clin Microbiol 1994; 32:1586-1588.

16. Knapp J, Centers for Disease Control and Prevention (CDC). B88 Neisseria gonorrhoeae Reference Strains For Antimicrobial Susceptibility Testing. CDC; 2005.

17. Antunes GS, Damasceno CAV, Cisalpino EO. Perfil de suscetibilidade de Neisseria gonorrhoeae a antimicrobianos em Belo Horizonte, MG. Rev Microbiol 1984; 15:217- 221.

18. Ferreira WA, Vasconcelos WA, Silva MF, Gomes JS, Ferreira CM, Benzaken AS. Resistência da Neisseria gonorrhoeae A Antimicrobianos Em Manaus: Período 2005-2006. J Bras Doenças Sex Transm 2007; 19:65-69.

19. Belda Jr W, Velho PENF, Fagundes LJ, Arnone M. Brief communication evaluation of the In Vitro activity of six antimicrobial agents against Neisseria gonorrhoeae. Rev Inst Med Trop São Paulo 2007; 49:55-58.

20. Barreto NA, Sant'anna RRP, Silva LBG, Uehara AA, Guimarães RC, Duarte IM. Caracterização Fenotípica E Molecular De Neisseria gonorrhoeae Isoladas No Rio de Janeiro, 2002-2003. J Bras Doenças Sex Transm 2004; $16: 32-42$

21. Dillon JR, Ruben M, Li H, Borthagaray G, Màrquez C, Fiorito S. Challenges in the Control of Gonorrhoea in South America and the
Caribbean: Monitoring the Development of Resistance to Antibiotics. Sex Transm Dis 2006; 33:87-95.

22. Gonococcal Antimicrobial Susceptibility Surveillance in Latin America and the Caribbean. Report of the Wokshop for the Revitalization of the Gonococcal Antimicrobial Susceptibility Surveillance Program in Latin America and the Caribbean (GASP-LAC), Buenos Aires, Argentina.2-4 November 2010. [Cited_2011 December 12]. Available from: http://www. gasp-lac.net/docs/GASP-LAC_Meeting_Report_FINAL_Addendum.pdf /

23. Cao V, Ratsima E, Tri DV, Bercion R, Fonkoua MC, Richard V, et al. Antimicrobial Susceptibility of Neisseria gonorrhoeae Strains Isolated in 2004-2006 in Bangui, Central African Republic; Yaoundé, Cameroon; Antananarivo, Madagascar; and Ho Chi Minh Ville and Nha Trang, Vietnam. Sex Transm Dis 2008; 35:941-945.

24. Ieven M, Looveren MV, Sudigdoadi S, Rosana Y, Goossens W, Lammens C, et al. Antimicrobial Susceptibilities of Neisseria gonorrhoeae Strains Isolated in Java, Indonesia. Sex Transm Dis 2003; 30:25-29.

25. Magalhães M. Uretrite causada por Neisseria gonorrhoeae produtora de penicilinase: relato de um caso. Rev Bras Pat Clin 1984; 20:116-118.

26. Enders M, Turnwald-Maschier A, Regnath T. Antimicrobial resistance of Neisseria gonorrhoeae isolates from the Stuttgart and Heidelberg areas of southern Germany. Eur J Clin Microbiol Infect Dis 2006; 25:318-322.

27. Ministério da Saúde. Secretaria de Vigilância em Saúde. Programa Nacional de DST e Aids. Manual de Controle das Doenças Sexualmente Transmissíveis. Brasília: Ministério da Saúde; 2006.

28. Belda Jr W, Velho PENF, Arnone M, Fagundes LJ. Emergence of Fluoroquinolone-Resistant Neisseria gonorrhoeae in São Paulo, Brazil. Braz J Microbiol 2007; 38:293-295.

29. Uehara AA, Amorin ELT, Ferreira MF, Andrade CF, Clementino MBM, Filippis I, et al. Molecular Characterization of Quinolone-Resistant Neisseria gonorrhoeae Isolates from Brazil. J Clin Microbiol 2011; 49:4208-4212.

30. Starnino S, Galarza P, Carvallo MET, Benzaken AS, Ballesteros AMRT, Cruz OMS, et al. Retrospective Analysis of Antimicrobial Susceptibility Trends (2000-2009) in Neisseria gonorrhoeae Isolates from Countries in Latin America and the Caribbean Shows Evolving Resistance to Ciprofloxacin, Azithromycin and Decreased Susceptibility to Ceftriaxone. Sex Transm Dis 2012; 39:813-821.

31. Tanaka M, Kumazawa J, Matsumoto T, Koboyashi I. High prevalence of Neisseria gonorrhoeae strains with reduced susceptibility to fluoroquinolones in Japan. Genitourin Med 1994; 70:90-93.

32. Newman LM, Moran JS, Workowski KA. Update on the Management of Gonorrhoea in Adults in the United States; Clin Infect Dis 2007; 44 (suppl 3):84-101.

33. Ferreira WA, Ferreira CM, Naveca FG, Almeida NCO, Vasconcelos WS, Gomes JS, et al. Genotyping of two Neisseria gonorrhoeae fluroquinoloneresistant strains in the Brazilian Amazon region. Mem Inst Oswaldo Cruz 2011; 106:629-631. 